\title{
Incorporating a Gender Perspective into Cuba's Health System: Realities and Challenges
}

\section{Leticia Artiles MS PhD}

\begin{abstract}
The article describes progress and challenges in incorporating a gender perspective into the Cuban health system. Results obtained thus far indicate progress in raising consciousness and in concentration on the interaction between biological and social factors, in particular recognizing gender as a social determinant of health. Weaknesses are also identified, and recommendations made for introduction of a gender perspective in various areas of the health system such as policy making; services planning, organization and delivery; population health assessments; and human resources training and development.
\end{abstract}

KEYWORDS Gender issues, gender bias, health care systems, delivery of health care, Cuba

\section{INTRODUCTION}

The evolution of gender perspective's incorporation into health systems has gone hand in hand with the advance of women's position in social movements. In the 1970s and 1980s, the approach to studying female social disadvantage was limited to 'what women lack,' relying on the implicit assumption that the problem resided in women themselves.[1] As a result, in the health field the articulation of gender was reduced to maternal and child health, women's morbidity and mortality indicators and, at best, comparisons of women's health to men's.[2] In effect, this resulted in a symbolic equation of woman with mother, with family, in turn generating myths of femininity that influenced all areas of a woman's life, irrespective of any other factors.[3] According to this equation, a woman is educated for her roles of good mother and wife, the axis of feminine subjectivity. Health systems and their organization do not escape these assumptions.[4]

The binary concept of masculinity and femininity based on biological sex has changed over time. More recently, conceptualization of sex has evolved considerably, expanding to embrace the concept of gender, which goes beyond physiological considerations to contemplate the social construction of functions, stereotypes and prejudices that have hindered women's equality and their full exercise of economic, social and cultural rights.[5] Adopting a gender perspective in health planning, policies and programs implies identifying, analyzing and acting on health inequalities derived from interactions between sex and gender differences and other forms of inequality such as socioeconomic status, age, ethnicity, sexual orientation and functional capacities.

Applying a gender perspective A gender perspective articulates a subject's position, a point of view; constitutes a point of departure and an endpoint; delimits the field of observation; proposes a meaning for what is observed; and defines criteria for describing, interpreting and explaining the phenomena observed. [6] This construction lays the basis for women and men having different outlooks, resulting in visions of femininity and masculinity involving imagery, symbolic structures and representations stemming from different paths and starting points. An understand- ing of these complexities and differing outlooks is essential for any person, man or woman, to apply a gender perspective. In the health field, consciousness must be coupled with skills to apply this perspective in any arena, from development of public policy to patient care.

Regional policies PAHO's 46th Governing Council approved a Plan of Action for Implementing the Gender Equality Policy 2009_ 2014 , whose aim is to help achieve gender equality in health status and development through research, policies and programs that pay due attention to gender differences in health and health determinants and actively promote equality between women and men.[5,7] PAHO has urged member states to include such a policy in their activities. In my opinion, Cuba's unified health care system gives it a relative advantage in the potential to fully apply a gender perspective, compared to other countries in the Americas that have health care delivery systems fragmented along public, private and social security lines.

This paper assesses Cuba's progress in incorporating a gender perspective into its health system over the last few years, identifying current strengths, weakness and challenges that affect prospects for its thoroughgoing application. I will also propose some considerations-effectively, recommendations-concerning several actions that would favor extension of this perspective to various areas of Cuba's health system.

\section{CUBA'S POTENTIAL}

Cuba's relative advantage in prospects for incorporating a gender perspective in health stems first from the political will of government, in keeping with its focus on social justice and its continued commitment to eliminate all forms of discrimination-whether by class, gender or race-as reflected in the Council of State's resolution approving and enacting the National Action Plan following the Beijing conference.[8] Such political will is key to analyzing and introducing a gender perspective in health policies, strategies, statistics, programs, research and projects to improve health services, incorporating social factors, particularly gender, not simply as variables but as tools and standards for improved decision making.

Added to this strength is the fact that Cuba has a unified and integrated health system, not fragmented into private, public and other service delivery schemes as in some other countries. This permits periodic auditing and inspections that help ensure adequate program implementation at all levels throughout the country. Moreover, results from research at health sciences universities are deposited directly into the health system, since these universities are under the jurisdiction of the Ministry of Public Health (MINSAP, its Spanish acronym), facilitating introduction of findings into practice. Thus, a gender perspective explicitly included in MINSAP's mission, vision and strategy would have more likelihood of being organically applied throughout the sector. However, when it comes to gender, the advantage of a single, unified health system has been insufficiently leveraged for greater equity, a value inherent in Cuban health care. 


\section{Perspective}

This and other weaknesses translate into challenges to be faced in order to take advantage of existing opportunities to determine which interventions to implement, relying on process and implementation analysis of health promotion, disease prevention, curative care and rehabilitation actions.

\section{TOWARDS A GENDER PERSPECTIVE IN CUBA'S HEALTH SYSTEM}

MINSAP has no explicit gender policy. However, the health system's free, universal coverage offers equal access by men and women to resources for their health and wellbeing, contributing to the goal of achieving "higher levels of health protection for the entire population," as stated in MINSAP's strategy document providing public health projections through 2015 . The same document recognizes the continuing challenge of improving attention to "special population groups," including women, as well as priority for research in areas such as men who have sex with men. However, comprehensive consideration of gender-specific needs constitutes a pending agenda.[9]

Thus, there is no single structure devoted to gender in MINSAP. However, several national centers have been assigned the role of promoting a gender perspective: the National Health Promotion and Education Center (CNPES, its Spanish acronym), the National STI/HIVIAIDS Prevention Center (CNPITS/VIH/SIDA, its Spanish acronym); the National Center for Sex Education (CENESEX, its Spanish acronym); the National School of Public Health (ENSAP, its Spanish acronym); and the 14 medical universities across the country. Most of the provincial medical universities have women's studies units, meant to raise awareness among students and faculty of the importance of considering gender in research and analysis of health information.

A notable step forward is disaggregation by sex of data in MINSAP's Health Statistics Yearbook, and the calculation of the sex ratio for consideration of morbidity, mortality and other health statistics, important information for gender analysis.[10] In addition, since 2009, MINSAP's Science and Technology Division has included in its research priorities women's and men's perceptions in identifying gender-specific practical and strategic needs, as social determinants of health.[11]

MINSAP has strengthened its human resource capacity-building, both centrally and in centers such as CNPES, CNPITS/VIH/SIDA, CENESEX, the National Maternal-Child Health Program, women's studies and sex education units at medical universities and in a research and training center on gender located in ENSAP.

Civil society has been an important player in this process, as in other health-related activities. In this regard, the role of the Federation of Cuban Women (FMC, its Spanish acronym) deserves particular mention, including its Women's and Family Centers and neighborhood health promoters. Other neighborhood organizations also assist in MINSAP vaccination and cancer screening, among other programs. Together with the local FMC, they sponsor health forums, providing information and opportunities to discuss issues of interest to women and related to gender equity in the family and community.

Also in the realm of civil society: the Gender and Health Network, the Latin American Social Medicine Society affiliate in the Cuban Society of Public Health, promotes and supports training, research and publications to strengthen knowledge of social determinants of health and gender perspective. And finally, the Cuban Society of Family Medicine and the Menopause Division of the Cuban Obstetrics and Gynecology Society include gender issues in their training and research activities.

\section{CHALLENGES AHEAD}

We still have some distance to go to bring gender analysis into the decision-making process, with gender-inflected epidemiologic profiles and exploration of gender intersectionalities[12] with social status, geography, ethnicity, abilities, life stage and sexual diversity. We need to lay out a strategy to strengthen this process, training change agents who will move actions forward greater incorporation of a gender perspective. To consolidate progress to date and move ahead, health professionals are needed who have training and sensitivity to social medicine and the competencies necessary to extend a gender perspective to all areas of health service management and delivery.

Health policies In addition to more capacity building, if they are to influence policy towards incorporation of a gender perspective, Cuban health professionals also need access to data disaggregated by sex and to have thorough knowledge of sociological factors: social contexts; health-related cultural beliefs, attitudes and cultural practices; housing and sanitary conditions relevant to the distribution of women's and men's domestic roles; gender-influenced access to power, to public office and decision making at all levels; and in any related spheres in which inequities affect health.

To introduce a gender perspective in public policies, those who participate in their formulation and application must recognize: the economic value of unpaid work and reproduction, division of labor by gender, intergender subordination as a health risk factor for men and women and as a determinant of vulnerability for some social groups; the status of women and their real opportunities in the labor market; differences in opportunities for women and men in the public sphere and in access to power; and sex-specific impact of biological and social factors on health and differing health needs. Such recognition by those who design public policies demands true sensitivity, not just lip service, to the influence of gender on health. Incorporating this perspective in decision making will facilitate more integrated and humane development in all spheres of the health system.

Health services planning Moser identified six basic tools for gender-based planning: identification of gender roles, consideration of differences in access to and control of resources, assessment of gender-specific needs, role balance and intersectoral planning, relation between roles and needs, and inclusion of stakeholders in the planning process.[13] Weissman further recommends including nature-of-care needs; differential socialization patterns regarding symptom recognition, disease perception and serviceseeking behavior; and structural and institutional factors that differentially facilitate or obstruct health service access.[14]

Gender-based planning also implies political decisions about the changes a gender perspective can introduce in institutional power structures in the medium and long term (for example, greater participation by women in leadership of the health system); review and adaptation of institutional structures and procedures to create capacity for gender-based project planning and implementation; and implementation and evaluation tools for gender analysis and health problem definition. 
Health service organization Health services are usually evaluated with a pronounced medical bias, by improvements in health indicators, mortality reduction or increased efficiency. Criteria such as needs satisfaction or exercise of client rights are usually not considered; at most, expressions of satisfaction are mentioned. Omitting a gender analysis misses the point that, "those who don't decide don't expect, and hence, they ask for very little, generating self-congratulatory evaluations," from people grateful for whatever they may receive.[15]

Including a gender perspective in health care quality must include everything from treating people respectfully, cleanliness and adequate signage to shared decision making between health care provider and patient, which means active patient participation as subjects throughout the health care process, within their own social context. This in turn implies strengthening the social medicine model as opposed to the traditional doctor-centered model of care.

Globally, inclusion of a gender perspective in health services has become more common in recent decades, but still tending to focus more on women's health. Some authors argue for more attention to men's health, since men tend to die younger and from preventable causes such as intentional and unintentional injuries, myocardial infarction, cancer, cirrhosis and drug addiction, with higher rates of suicide as well.[16] This reminds us that gender does not equal women: rather, it is a conceptual tool to enrich explanatory models of health and illness, amplify epidemiologic profiles and recontextualize planning for health interventions and programs.

Population health assessment Health surveillance from a gender perspective is meant to gather, organize, analyze and use information that enables application of this perspective in the planning, organization and systematization of health services management. It can strengthen the design of policies, plans and programs to better respond to sex-specific needs and help reduce gender-based inequities in health and human development.

Epidemiologic surveillance from a gender perspective requires tackling the epidemiology of inequality, obtaining information for sex-specific epidemiologic profiles-with all their intersectionalities-and identifying modifiable differences. Current information is inadequate because in most countries data collection instruments are insufficiently detailed for analysis by sex.[1,7] In Cuba, sex-specific data are available but gender analysis is still lacking, with insufficient characterization of the social contexts of individuals and populations whose health inequalities generate different needs requiring different responses.

To obtain and analyze information from a gender perspective, one has to begin by recognizing the inequality existing between the sexes, within and beyond the biological and reproductive. This also requires acknowledging the impact of their roles, including differences in assigned and assumed social burdens, on the health-illness continuum; and must take into account the particular needs, contributions, risks and opportunities of each sex, stemming not only from biological differences but also from the way women's and men's positions are articulated in the social, political and economic realms.

Surveillance and population health assessment require health profiles that identify and analyze differences according to sex and their determinants within particular population subgroups. This analytic approach requires not only identification of similarities and differences between the sexes but also intragender variations, resulting from differences in living conditions across population subgroups.

Thus, including a gender perspective in epidemiologic surveillance systems requires defining and selecting new problems that merit surveillance, as well as determining appropriate indicators and methods for data collection and analysis.

This is a challenge that, if met, will improve health system and service quality. It is a broad undertaking and one that requires deeper study after application in practice.

\section{FINAL CONSIDERATIONS}

In Cuba, the health sector's institutional development and policies espoused by $\mathrm{PAHO}, \mathrm{WHO}$ and the FMC have facilitated gradually increasing application of a gender perspective in the health system. The existence of a Beijing followup plan and government commitment to the various international conferences on the topic in recent decades, coupled with political and social will should ensure continued progress in this area. Explicit inclusion of the following areas should be improved as we move forward:

- Establish a comprehensive human resource development strategy in health that includes a gender perspective in education and training, as well as capacity building for practitioners and decisionmakers;

- Recognize biological diversity and the inequitable distribution of power and social burdens assigned as a function of sex;

- Eliminate health professionals' attitudes that stereotype classification of health care demands by sex (men: more serious health problems; women: problems more emotional in nature);

- Recognize sexual diversity and its intersectionalities as determinants of health and gendered epidemiologic profiles;

- Recognize gender-associated risk factors;

- Incorporate contributions of roles and functions in public and private life and the connections between these to make genderinformed clinical and epidemiologic diagnoses; and

- Incorporate gender as a determinant of health in all areas and processes of the health sector. $-1 /$ -

\section{REFERENCES}

1. Gómez E. Curso Virtual de Género y Salud. Washington: Pan American Health Organization; 2010. Marco Conceptual. Spanish.

2. Estrada JH. La articulación de la categoría género y salud: un desafío inaplazable. Rev Gerenc Polit Salud. 2009 Jun - Dec;8(17):106-22. Spanish.

3. González I. La infertilidad, el maternaje frustrado. Rev Cubana Med Gen Integr. 2002;18(3):233-5. Spanish.
4. Arés P. Género, salud y cotidianidad. Havana: Ed. Científico Técnica; 2000. Spanish.

5. Política de Igualdad de Género. Resolución CD46.R16. 46 ${ }^{\mathrm{a}}$ Consejo Directivo de la OPS. Washington, D.C: Pan American Health Organization; 2005. Spanish

6. González Vélez C, Sánchez Buitrago M. La investigación en salud para el desarrollo y el enfoque de género: una contribución necesaria para la equidad en salud. Red de Salud de las Mujeres Latinoamericanas y del Caribe (RSMLAC). Bangkok; 2000. Spanish.

7. Plan de Acción para la implementación de la Política de Igualdad de Género de la Organización Panamericana de la Salud 2009-2014. Washington, D.C: Pan American Health Organization; 2005. Spanish. 


\section{Perspective}

8. Council of State (CU). Plan de Acción Nacional de Seguimiento a la Conferencia de Beijing. Havana: Gaceta Oficial de la República de Cuba. 1997 May 5. Spanish

9. Proyecciones de la Salud Pública en Cuba para el 2015. Havana: Ministry of Public Health (CU); 2006. 68 p. Spanish.

10. National Health Statistics Bureau (CU). Anuario Estadístico de Salud 2005. Havana: Ministry of Public Health (CU); 2006. Spanish.

11. Knowledge Management and Technology Agency (CU). Identificación y sistematización de prioridades para la investigación en salud. Informe de Investigación. Havana: Ministry of Pubic Health (CU); 2009. Spanish.

12. Nash JC. Re-thinking Intersectionality. [Internet] Feminist Rev. 2008 [cited 2012 Apr 6];89:1-15.
Available from: http://www.palgrave-journals .com/fr/journal/v89/n1/full/fr20084a.html

13. Moser C. Gender Planning and Development: Theory, Practice and Training. London: Routledge; 1993 Sep. $304 \mathrm{p}$.

14. Weissman C. Women's health care. Baltimore: The Johns Hopkins University Press; 1998.

15. Matamala M, Berlagosky F. Salazar G, Nuñez L. Calidad de atención en salud reproductiva desde un enfoque de género. Investigación cualitativa con mujeres beneficiarias del Servicio de Salud Occidente de la Región Metropolitana, Santiago de Chile.1998. [Santiago]: [publisher unknown]; 1998. Spanish.

16. Tajer D. Heridos corazones: subjetividad y vulnerabilidad coronaria en varones y mujeres.
Buenos Aires: Editorial Paidós Tramas Sociales 57; 2009. 296 p. Spanish.

THE AUTHOR

C. Leticia Artiles Visbal (leticia@infomed.sld. $\mathrm{cu})$, anthropologist with a doctorate in health sciences, Havana.

Submitted: October 23, 2011

Approved for publication: April 13, 2012

Disclosures: None 